\title{
Formação docente e a mediação de conflitos na escola
}

\author{
Formación docente y la mediación de conflictos en la escuela \\ Teacher training and conflict mediation in school
}

\author{
Ivonte Afonso Jodar ${ }^{1}$ \\ Lúcio Jorge Hammes ${ }^{2}$
}

\begin{abstract}
Resumo
Este artigo apresenta resultados de uma pesquisa de intervenção com pressupostos da abordagem qualitativa, desenvolvida com docentes, durante um curso de formação de mediadores, de uma escola municipal de Jaguarão-RS. O objetivo era qualificar os docentes para contribuir com a resolução de conflito no ambiente escolar. Propôs-se evidenciar ações na escola, decorrentes de um ambiente cooperativo e aquelas ações que revelam um ambiente de coação, construindo estratégias de mediação para enfrentar as manifestações de violência. A partir dos dados coletados foi possível identificar que as ações docentes requerem flexibilidade do planejamento pedagógico fundamentado no diálogo em busca de um aprendizado dos princípios de uma educação para a paz. Os resultados indicam para a necessidade de formar pessoas para a mediação de conflitos.
\end{abstract}

Palavras-Chave: Docência. Violência na escola. Conflitos.

\section{Resumen}

Este artículo presenta resultados de una investigación de intervención con presupuestos del abordaje cualitativo, desarrollada con docentes, durante un curso de formación de mediadores, de una escuela municipal de JaguarãoRS. El objetivo era calificar a los docentes para contribuir con la resolución de conflictos en el ambiente escolar. Se propuso evidenciar acciones en la escuela, derivadas de un ambiente cooperativo y aquellas acciones que revelan un ambiente de coacción, construyendo estrategias de mediación para enfrentar las manifestaciones de violencia. A partir de los datos recolectados fue posible identificar que las acciones docentes requieren flexibilidad de la planificación pedagógica fundamentada en el diálogo en busca de un aprendizaje de los principios de una educación para la paz. Los resultados indican la necesidad de formar personas para la mediación de conflictos.

Palabras claves: Docencia. Violencia en la escuela. Los conflictos.

\begin{abstract}
This article presents results of an intervention research with assumptions of the qualitative approach, developed with teachers, during a course of training of mediators, from a municipal school in Jaguarão-RS. The objective was to qualify teachers to contribute to conflict resolution in the school environment. It was proposed to highlight actions in the school, resulting from a cooperative environment and those actions that reveal an environment of coercion, constructing mediation strategies to face manifestations of violence. From the collected data it was possible to identify that the educational actions require the flexibility of pedagogical planning based on the dialogue in search of a learning of the principles of education for peace. The results indicate the need to train people to mediate conflicts.
\end{abstract}

Keywords: Teaching. Violence in school. Conflicts.

\footnotetext{
${ }^{1}$ Mestranda em Educação - Universidade Federal do Pampa (UNIPAMPA). Jaguarão/RS (Brasil). E-mail: ivonete.jag@gmail.com.

${ }^{2}$ Doutor em educação. Professor da Universidade Federal do Pampa (UNIPAMPA). Jaguarão/RS (Brasil); Email:1uciojh@gmail.com.
} 


\section{Introdução}

Somos bombardeados constantemente com notícias de violência na escola, deparando-nos com o fenômeno da violência entre os estudantes e pessoas envolvidas na comunidade escolar. Há cenas de agressividade entre alunos, consequência do uso de drogas, resultando em furtos, indisciplina, depredações e desrespeito com os profissionais que nela atuam. Muitos professores ainda se sentem despreparados, inseguros e intimidados para lidar com essa problemática nesta instituição socializadora e mediadora dos conhecimentos.

Álvaro Chrispino (2007) em seu artigo "Gestão do conflito escolar: da classificação dos conflitos aos modelos de mediação", apresenta o resultado de uma pesquisa sobre a importância que o jovem atribui à educação, à escola e ao professor, ao mesmo tempo em que apresenta sua preocupação com a violência. Discute os conceitos de conflito e de conflito escolar, trazendo fundamentação teórica sobre os tipos de conflito, relacionando aos diferentes paradigmas e contexto, apresentando maneiras de classificar os conflitos e os conflitos escolares. Neste estudo, percebe-se a preocupação em definir os tipos de conflitos existentes, buscando o entendimento a partir da reflexão científica.

Conflito é toda opinião divergente ou maneira diferente de ver ou interpretar algum acontecimento. A partir disso, todos os que vivemos em sociedade temos a experiência do conflito. Desde os conflitos próprios da infância, passamos pelos conflitos pessoais da adolescência e, hoje, visitados pela maturidade, continuamos a conviver com o conflito intrapessoal. (CHRISPINO, 2007, p15)

Neste sentido, o artigo apresenta um problema emergente e traz considerações teóricas e dados de uma intervenção que permitem discutir a temática proposta. O Estudo indica que a mediação de conflito pode ser uma alternativa potente e viável para a diminuição da violência escolar, como uma forma de solucionar o problema.

Segundo Chrispino (2007) um exemplo claro da dificuldade que temos para lidar com o conflito é a nossa incapacidade de identificar as circunstâncias que derivam do conflito ou redundam nele. Em geral, nas escolas e na vida, só percebemos o conflito quando este produz suas manifestações violentas.

No contexto da escola em que atuamos foi considerado necessário uma ação que capacitasse os professores a atuarem em situações de conflito que muitas vezes desencadeiam comportamento violento entre os alunos e estes com os professores. De acordo com os dados coletados havia muitas ocorrências registradas em atas ou fichas individuais de alunos do atendimento do Serviço de Orientação Educacional. A leitura destes dados instigou-nos a propor o curso que analisamos neste artigo. 


\section{Metodologia do estudo}

Este estudo teve uma abordagem metodológica qualitativa, intervencionista a partir de um curso de extensão universitária, no formato de oficinas numa perspectiva freireana, propiciando a criação de um espaço onde prevaleceu a fala e a escuta qualificada.

A população do estudo foram onze professoras que lecionam do $5^{\circ}$ ao $9^{\circ}$ ano do ensino fundamental e equipe diretiva da escola. As oficinas com os profissionais possibilitaram o estudo, a reflexão e discussões sobre a problemática, da manifestação de situações de violência no contexto escolar onde foram propostos 7 encontros de formação presencial com oficinas e trabalhos à distância que se constituíram em experiências pedagógicas importantes para análise do trabalho educacional, assim como uma oportunidade de formação dos profissionais que atuam na escola.

Segundo Candau (1995), a oficina constitui um espaço de construção coletiva do conhecimento, de análise da realidade, de um confronto e troca de experiências. Nessa metodologia, é fundamental a criatividade, a sensibilidade, a amorosidade, a alegria, o envolvimento do educador. Na oficina pedagógica, educadores e educandos são co-criadores na produção do conhecimento. Aprender é uma aventura criadora, algo, por isso mesmo, muito mais rico do que meramente repetir a lição dada. Aprender para nós é construir, reconstruir, constatar para mudar, o que não se faz sem abertura ao risco e à aventura do espírito (FREIRE, 1998, p.77).

\section{Discussão e resultados}

Tardif e Raymond (2000) destacam como fenômenos importantes a serem considerados no ambiente escolar a trajetória pré - profissional e a trajetória profissional dos professores. Para estes autores saber como viver numa escola é tão importante quanto saber ensinar na sala de aula, sendo importante que os professores assimilem também saberes práticos específicos aos lugares de trabalho, com suas rotinas, valores, regras, etc.

Lück (2010) ressalta a importância do clima e a cultura organizacional escolar para constituir-se na ambivalência em que se realiza o processo humano-social do fazer pedagógico, que expressa a personalidade e características da ambiência.

O processo educacional tem por objetivo o desenvolvimento social dos alunos, sua formação para a cidadania, sua realização depende sobremodo de que o ambiente escolar apresente qualidade e características compatíveis com os resultados pretendidos, isto é, que seu modo de ser e de fazer, suas relações interpessoais e sociais, seus valores, entre outros aspectos, sejam de tal natureza que correspondam aos valores e expressões da cidadania e que esses aspectos possam ser observados, 
analisados e compreendidos em sua vivência e que se aprenda a partir dessa experiência.( LÜCK ,2010, p. 40).

Presenciamos ainda conversas entre colegas professoras na sala dos professores da escola, onde uma conta para a outra num tom de admiração que alguns de seus alunos do $6^{\circ}$ ano "ainda" querem dar beijo na professora, dizendo como são infantis, e a colega complementando o comentário referindo a outro aluno que já está no $8^{\circ}$ ano e sempre a beija quando chega na sala de aula. Tais comentários entre as professoras deixam claro que isto não é mais comum, e que estão tão acostumadas com alunos indisciplinados que quando encontram alunos mais afetuosos parece não ser normal, colocando em questão a idade destes.

Segundo Lück (2010) é reconhecido como ensino de qualidade aquele que se assenta não sobre conhecimentos formais estanques, e sim sobre saberes socialmente valorizados e necessários para o enfrentamento dos desafios de desenvolvimento pessoal e social dos alunos, neste sentido percebe-se que as professoras não conseguiram valorizar esta virtude dos alunos, denominando como um comportamento infantilizado o ato de cumprimentar a professora com um beijo.

Promover um ambiente saudável e seguro em sala de aula é fundamental na redução da violência escolar. Estudantes precisam ver e reconhecer que os professores, diretores e auxiliares são capazes de se importar e intervir na situação da violência em sua escola, mas a maioria dos professores ainda não sabe qual a melhor forma de amenizar as relações de conflito e até mesmo de violência verbal, física ou psicológica no dia a dia do professor e alunos.

Os estudos das fichas individuais de alunos do atendimento do Serviço de Orientação Educacional revelam casos de agressão que ocorrem por falta da intervenção de professores e ou da equipe pedagógica. Isso se dá não só pelo fato de não se importarem, mas por não terem um conhecimento amplo a respeito deste fenômeno e não saberem como intervir de forma eficaz. Por este motivo, tornou-se importante a capacitação de todos os profissionais da área educacional, e todos que, de alguma forma, exercem função em um ambiente escolar, a fim de prepará-los para prevenir e combater a violência em sua escola local, de forma prática e duradoura.

Segundo Perrenoud (2005, p. 34):

É preciso urgentemente buscar inspiração nas aquisições da Pedagogia institucional (...) para aglutinar o conjunto de iniciativas complementares e de níveis de ação: a educação para a cidadania, assim como toda educação- diferentemente de um ensino- passa por experiências de vida e de relação com o saber que têm efeitos formativos. Assim como a língua, a cidadania se aprende na prática. 
O PNE (2014) prevê em seu artigo $2^{\circ}$, diretrizes sobre a educação para a cidadania, destacando dentre suas estratégias garantir políticas de combate à violência na escola, inclusive pelo desenvolvimento de ações destinadas à capacitação de educadores para detecção dos sinais de suas causas, como a violência doméstica e sexual, favorecendo a adoção das providências adequadas para promover a construção da cultura de paz e um ambiente escolar dotado de segurança para a comunidade.

Em consonância com os princípios citados, o Plano Nacional de Educação em Direitos Humanos (PNEDH), aprovado em 2006, estabelece a educação e a escola como espaços privilegiados para a promoção de uma nova cultura em direitos humanos, de modo a possibilitar que os avanços conquistados no plano normativo também se concretizem como orientações para valores e condutas dos cidadãos brasileiros. A escola, nesse sentido, teria o papel de desenvolver valores que promovam a dignidade da pessoa, garantindo o respeito ao aluno, aos professores e a toda a comunidade escolar, entendidos como sujeitos de direitos.

Tuvilla Rayo (Apud PIGATTO, 2010) evoca a importância da Educação para a Paz para contribuir com a formação de sujeitos que possam promover a implementação dos Direitos Humanos e superar obstáculos que impedem a promoção da vida. Para o autor, a Educação para a Paz precisa ser compreendida e trabalhada de modo que seja uma "resposta à problemática mundial a partir da ótica dos direitos humanos”, alicerçada na cooperação, no diálogo e no intercâmbio entre indivíduos e sociedades.

Perpassando pela formação inicial dos professores, onde segundo Garcia (2010) começa a construção da identidade profissional e se prolonga durante todo o seu exercício profissional. Tal identidade não surge automaticamente como resultado da titulação. Mas, pelo contrário, requer a construção, modelando-a. Exige um processo individual e coletivo de natureza complexa e dinâmica, o que conduz à configuração de representações subjetivas acerca da profissão docente.

A temática da identidade docente se refere a como os docentes vivem subjetivamente seu trabalho e a quais são os fatores básicos de satisfação e insatisfação. Também está relacionada com a diversidade de suas identidades profissionais e com a percepção do ofício por parte dos próprios docentes e pela sociedade na qual desenvolvem suas atividades. A identidade docente é tanto a experiência pessoal como o papel que lhe é reconhecido/atribuído numa dada sociedade. (GARCIA, 2010, p. 19)

Conforme os professores que participaram da formação o tema sobre mediação de conflitos é bastante relevante para que possam se capacitar para prevenir a violência. Uma das professoras entrevistada afirma que: 
A violência no meio escolar é um assunto bastante complexo, visto que não há fórmulas mágicas para solucionar o problema.

Já, uma outra professora, participante da formação, afirmou:

Os pais, de certa forma, perderam o controle sobre os filhos. Há uma inversão de valores, os filhos mandam e os pais obedecem e com isso os pais empurram o problema para a escola resolver.

Questionadas sobre a possibilidade de desenvolver uma ação sobre a problemática da violência no meio escolar, as professoras responderam:

Embora acredite ser difícil fazer intervenções nesse problema é necessário tentar.

Não sei, pois muitas causas vêm de longa data por problemas de "n" carências sociais.

Sim, sempre. É na escola que devemos formar o cidadão/aluno.

$\mathrm{Na}$ avaliação de uma das oficinas intitulada "A educação para a Paz: História, necessidade e princípios", as professoras participantes escreveram que consideram estes momentos:

Ótimos, pois nos faz refletir sobre o cotidiano em que vivemos e avaliar o quanto ele nos induz à violência.

Bons, trazendo reflexões sobre o tema e apontando ideias para a promoção da paz no ambiente escolar.

Outra professora destacou a importância sobre o assunto:

É importante destacar que é um tema atual, que fomenta discussões relevantes socialmente, e nos permite estabelecer criticas com efeitos de compreensão sobre o processo cotidiano que deve ser a educação para a paz.

$\mathrm{Na}$ análise consideramos que o contexto escolar, assim como nos mostra Martins e Machado (2016) a ocorrência de situações de conflito e violência pode ser vista a partir de múltiplos fatores, especialmente quando parte-se do reconhecimento das especificidades e singularidades de cada escola. Neste sentido, implica levar em consideração os contextos sociais nos quais estão localizadas; a dinâmica de organização e funcionamento pedagógico e administrativo; as demandas configuradas pelo escopo normativo de órgãos centrais e os fatores econômico-sociais e culturais. Segundo esta análise, as unidades de ensino precisariam se preparar para enfrentar contextos adversos, pois são inúmeras as dificuldades para implementar posturas mais adequadas no enfrentamento de conflitos, geralmente 
oriundos de situações não resolvidas ou, no limite, mal resolvidas, provocando (re)ações que podem chegar a agressões físicas.

O desenvolvimento profissional docente inclui todas as experiências de aprendizagem natural e aquelas que, planificadas e conscientes, tentam, directa ou indirectamente, beneficiar os indivíduos, grupos ou escolas e que contribuem para a melhoria da qualidade da educação nas salas de aula. É o processo mediante o qual os professores, sós ou acompanhados, revêem, renovam e desenvolvem o seu compromisso como agentes de mudança, com os propósitos morais do ensino e adquirem e desenvolvem conhecimentos, competências e inteligência emocional, essenciais ao pensamento profissional, à planificação e à prática com as crianças, com os jovens e com os seus colegas, ao longo de cada uma das etapas das suas vidas enquanto docentes (DAY, 1999, p. 4);

De acordo com as palavras de Freire (1998, p. 43) "é na formação permanente dos professores, o momento fundamental é o da reflexão crítica sobre a prática. É pensando criticamente a prática de hoje ou de ontem que se pode melhorar a próxima prática”.

\section{Repercussões da formação docente na sala de aula}

Uma das consequências constatadas, tão logo as professoras participaram da formação no formato de oficinas, foi o desenvolvimento de ações das professoras junto aos alunos em sala de aula. A partir desta formação, desenvolveram-se atividades bastante relevantes com os alunos, colocando em prática aquilo que foi discutido no grupo.

a) A turma do $7^{\circ}$ ano, por iniciativa da professora de ciências e a professora de educação física, construíram junto com os alunos um projeto sobre a Paz e Solidariedade. O objetivo deste projeto era estimular a solidariedade, valorizando a cooperação e refletindo sobre a importância da Paz. Os alunos, após estudo e reflexões em sala de aula, confeccionaram cartazes, escreveram redações e saíram em atividade extra muros, para arrecadar alimentos a fim de confeccionar cestas básicas a serem doadas na ocasião das festas natalinas à famílias carentes que os próprios alunos conhecem.

b) Os alunos envolvidos com o projeto também tiveram a iniciativa de fazer uma rifa de uma torta doce que foi confeccionada por uma mãe, para arrecadar fundos a fim de comprar brinquedos novos para as crianças, e mais alimentos para complementar as cestas básicas. Foi notável o entusiasmo dos alunos e o empenho das professoras neste projeto.

c) A professora do $5^{\circ}$ ano, juntamente com a professora que a substitui nos períodos de redução e a professora bibliotecária que também atende todos os alunos da escola, desenvolveram o Projeto "Cultura pela Paz", com atividades de reflexão a partir do filme: "Seleção Natural". O filme possibilitou aos alunos um vasto conhecimento sobre várias 
atitudes e modos que tomamos no nosso dia-a-dia desconstruindo a paz e ao mesmo tempo mostrou que podemos reconstruí-la. Após foram confeccionados cartazes em grupos , que foram distribuídos pelo ambiente escolar enfatizando o tema "Paz".

Os dados mostram que a formação pode levar a novas práticas, envolvendo alunos e comunidade numa dinâmica que leva a busca da construção de uma sociedade melhor.

\section{Considerações finais}

As discussões sobre a violência e a resolução de conflitos no ambiente escolar é um tema que está na ordem do dia a dia. A formação desenvolvida nesta escola municipal provocou reflexões muito proveitosas, pois possibilitou um espaço de debates sobre ideias e, dessa forma pensar sobre a prática docente em relação a mediação de conflitos.

Para o desenvolvimento da formação partiu-se do princípio de que para solucionar os conflitos é importante proporcionar o diálogo e discussões de forma democrática, a educação para a paz e os direitos humanos, a prevenção da violência e a criação de um clima pacífico e saudável que favoreça uma boa convivência escolar.

Os professores participantes consideraram o tema de total importância, visto que situações de conflito e violência na escola apesar de frequentes não são de fácil solução, é preciso orientação, pois um conflito mal resolvido pode evoluir para uma situação de violência.

\section{Referências}

BRASIL. Lei no 13005 de 25 de Junho de de 2014. Plano Nacional de Educação - PNE. Disponível em: <www.planalto.gov.br/ccivil_03/_ato2011-2014/2014/lei/113005.htm>. Acesso em: 26 Out. 2017.

CANDAU, Vera Maria et al. Oficinas pedagógicas de direitos humanos. $2^{\mathrm{a}}$ ed. Petrópolis, RJ: Vozes, 1995.

CHRISPINO, Álvaro. Gestão do conflito escolar: da classificação dos conflitos aos modelos de mediação. Ensaio: aval. pol. públ. Educ., Rio de Janeiro, v.15, n.54, p. 11-28, jan./mar. 2007. Disponível em: <http://www.scielo.br/pdf/ensaio/v15n54/a02v1554.pdf>. Acesso em nov. 2017.

FREIRE, Paulo. Pedagogia da autonomia: saberes necessários à prática educativa. $8^{\text {a }}$ ed. Rio de Janeiro: Paz e Terra, 1998.

GARCIA, Carlos Marcelo. O professor iniciante, a prática pedagógica e o sentido da experiência. Form. Doc., Belo Horizonte, v. 02, n. 03, p. 11-49, ago./dez. 2010. Disponível 
em: <http://formacaodocente.autenticaeditora.com.br/sumario/exibir/8>. Acesso em nov. 2017.

GARCÍA, Marcelo. Desenvolvimento Profissional: passado e futuro. Revista de Ciências da Educação n. ${ }^{\circ} 8 \cdot$ jan/abr 09. Disponível em

$<$ http://www.fep.porto.ucp.pt/sites/default/files/files/FEP/SAME/docs/Carlosmarcelo_Desenv _Profissional.pdf>. Acesso em nov. 2017.

LÜCK, Heloisa. Gestão da cultura e do clima organizacional da escola. Série Cadernos de Gestão. Vozes 2010.

MARCELO, Carlos. Desenvolvimento Profissional Docente: passado e futuro. Sísifo / revista de ciências da educação $\cdot$ n. ${ }^{\circ} 8 \cdot$ jan/abr 09. Disponível em:

<http://www.upf.br/_uploads/Conteudo/ppgecm/Desenvolvimento_profissional_docente.pdf> . Acesso em nov. 2017.

MARTINS, A. M.; MACHADO, C. Gestão escolar, situações de conflito e violência: campo de tensão em escolas públicas. Educar em Revista, Curitiba, Brasil, n. 59, p. 157-173, jan./mar. 2016. Disponível em: <http://www.scielo.br/scielo.php?pid=S0104-

$40602016000100157 \&$ script=sci_abstract\&tlng=pt $>$. Acesso em nov. 2017.

PERRENOUD, Philippe. Escola e cidadania: O Papel da escola na formação para a democracia. Porto Alegre: Artmed, 2005.

PIGATTO, Naime. A docência e a violência estudantil no contexto atual. Ensaio: aval. pol. públ. Educ., Rio de Janeiro, v. 18, n. 67, p. 303-324, abr./jun. 2010. Disponível em: <http://www.scielo.br/pdf/ensaio/v18n67/a07v1867.pdf>. Acesso em nov. 2017.

TARDIF, Maurice ; RAYMOND, Danielle. Saberes, tempo e aprendizagem do trabalho no magistério. Educ. Soc., 2000, vol.21, n.73, pp.209-244. Disponível em:

<http://dx.doi.org/10.1590/S0101-73302000000400013>. Acesso em nov. 2017. 